\title{
Impact of Heading Back and Pinching on Mineral Status of Moringa Leaves (Moringa oleifera Lam. Cv. PKM-1)
}

\author{
V. Divyabhrathi ${ }^{1}$, V.Swaminathan ${ }^{2}$, P. Paramaguru $^{3}$, K. Venkatesan ${ }^{4}$, \\ T. Anitha ${ }^{5}$ and T. Arumugam 4
}

${ }^{1}$ Department of Vegetable Science, Horticultural College and Research Institute, ${ }^{4}$ Department of Floriculture and Medicinal Crops, ${ }^{5}$ Department of Post-Harvest Technology, Tamil Nadu Agricultural University, Periyakulam, Theni, India

${ }^{2}$ Department of Horticulture, Agricultural College and Research Institute, Tamil Nadu Agricultural University, Madurai, India

${ }^{3}$ Horticultural College and Research Institute for Women, Tamil Nadu Agricultural

University, Tiruchirappalli, India

*Corresponding author

\begin{tabular}{|c|c|}
\hline & A B S T R A C T \\
\hline $\begin{array}{l}\text { Ke y w o r d s } \\
\text { Moringa, Heading } \\
\text { back, Pruning, } \\
\text { Nitrogen, } \\
\text { Phosphorous, } \\
\text { Potassium, } \\
\text { Calcium, } \\
\text { Magnesium }\end{array}$ & \multirow{3}{*}{$\begin{array}{l}\text { A field experiment was conducted to study the changes in mineral status of } \\
\text { moringa leaves after heading back and pinching treatments. Three heading back } \\
\text { treatments and three pinching treatments were imposed on the moringa trees. The } \\
\text { intensity of heading back and time of pruning is crucial for the stability of the tree, } \\
\text { proper light penetration and nutrient uptake. Less intensive heading back at } 70 \mathrm{~cm} \\
\text { above the ground level is beneficial in the uptake of } \mathrm{N}, \mathrm{P}, \mathrm{Ca} \text { and } \mathrm{Mg} \text {. Early } \\
\text { pruning at } 60 \text { days after heading back increased the uptake of mobile nutrients } \mathrm{P} \text {, } \\
\mathrm{K} \text { and } \mathrm{Mg} \text { while pruning at } 80 \text { days after heading back influenced the } \mathrm{N} \text { uptake } \\
\text { and late pruning at } 100 \text { days after heading back stimulated the higher } \\
\text { accumulation of } \mathrm{Ca} \text { in moringa leaves. In the interaction effect also heading back } \\
70 \mathrm{~cm} \text { with pinching at } 60 \text { days is beneficial to increase the mineral content (N, P, } \\
\mathrm{K}, \mathrm{Mg} \text { ) of annual moringa leaves except for calcium that prefers late pruning } \\
\text { at } 100 \text { days after heading back. }\end{array}$} \\
\hline Article Info & \\
\hline $\begin{array}{l}\text { Accepted: } \\
\text { 24 October } 2020 \\
\text { Available Online: } \\
10 \text { November } 2020\end{array}$ & \\
\hline
\end{tabular}

\section{Introduction}

Moringa (Moringa oleifera Lam.) popularly called as the 'drumstick tree' is an indigenous vegetable, has gained its importance due to its nutraceutical values and considered as an indispensable plant for health management. It is one of the most incredible plants to the mankind and its nutritional and medicinal properties have immense potential to manage malnutrition (Gopalakrishnan et al., 2016). The genus Moringa consists of 13 species but the most popular and cultivated type is Moringa oleifera, which is spread over in 
tropical and sub-tropical regions and adopts well in different soils and adjust well even in marginal conditions. The ability of this crop to survive adverse conditions made this crop to spread wide in various regions. This fast growing, small to medium sized tree is used as an animal forage, source of nutrition, medicine, water purification, cosmetics even as bio fuel.

Moringa is a pruning responsive crop and flowers in current season growth. Pruning is a prerequisite to maintain the proper canopy size and shape. Pruning also provides opportunity for easy harvest and increased quality content in moringa. Pruning in moringa removes the unproductive growth and helps to exploit its potential to a greater extent. Pruning also induces notable changes in the nutritional content of leaves and pods in moringa. The present study was carried out to find the effect of different stages of heading back and pinching on the mineral status of moringa leaves.

\section{Materials and Methods}

The trail was conducted at Department of Vegetable Science, Horticultural College and Research, Periyakulam, during 2018-19. The experiment was laid out in split plot design with two replications. Seeds of moringa cv. PKM-1 were sown in an area of 0.63 acre with a spacing of $3 \mathrm{~m} \times 3 \mathrm{~m}$. The main plot was imposed with heading back treatment and the sub-plot was with pinching treatments. The main-plot treatments include heading back at $30 \mathrm{~cm}\left(\mathrm{M}_{1}\right), 50 \mathrm{~cm}\left(\mathrm{M}_{2}\right)$ and $70 \mathrm{~cm}$ $\left(\mathrm{M}_{3}\right)$ above the ground level whereas the subplot treatments are pinching at 60 days $\left(\mathrm{S}_{1}\right)$, 80 days $\left(S_{2}\right)$ and 100 days $\left(S_{3}\right)$ after heading back.

The minerals status of the leaves was assessed at the vegetative stage after the completion of pinching treatments. The leaves were collected from five randomly selected trees of each treatment in each replication and used for analysis. The nitrogen content of the leaves was estimated by microkjeldahl block digestion and steam distillation method. Phosphorous was assessed in phosphoric vanadomolybdate yellow colour method, potassium in flame photometer, calcium by EDTA method and magnesium by versanate method. The data's obtained were statistically analysed as per the methods of Panse and Sukhatme (1967) using agres statistical software.

\section{Results and Discussion}

\section{Nitrogen content}

The nitrogen content was highest in 70 $\mathrm{cm}\left(\mathrm{M}_{3}\right)$ heading back (2.82 \%), pinching at 80 days $\left(\mathrm{S}_{3}\right)$ after heading back $(2.81 \%)$ and in the interaction $\mathrm{M}_{3} \mathrm{~S}_{2}$ (heading back at 70 $\mathrm{cm}$ followed by pinching at 60 days) with $2.87 \%$ (Table 1). The lowest nitrogen content was recorded in $50 \mathrm{~cm}\left(\mathrm{M}_{1}\right)$ headed back trees $(2.46 \%)$.Heading back at $70 \mathrm{~cm}$ and pinching at early stage enhances the number of branches which ultimately increased the nutrient uptake and translocation through transpirational pull. The results were in accordance with Thokchom et al., (2018) in apricot.

Mobility of nitrogen also aided its accumulation in increased vegetative growth (Kaith et al., 2011) resulted by the interaction of top heading back and early pinching in moringa. The result is in conformity with the findings of Cheng and Raba (2009) in apple

\section{Phosphorous content}

The main-plot treatment $\mathrm{M}_{1}$ (heading back at $30 \mathrm{~cm}$ ) and $\mathrm{M}_{3}$ of heading back at $70 \mathrm{~cm}$ $(0.020 \%)$ and the sub-plot treatment $\mathrm{S}_{1}$ $(0.022 \%)$ recorded the highest phosphorous 
content (Table 2). The interaction of $70 \mathrm{~cm}$ headed plants with pinching at 60 days $\left(\mathrm{M}_{3} \mathrm{~S}_{2}\right)$ recorded the highest phosphorous content of $0.026 \%$. Phosphorous content increases in severely pruned trees as it increases number of shoots and acted as active sink for nutrient (Singh et al., 2009). Much differences were not observed in the phosphorous content among the treatments could be possibly due to antagonism between the anions of nitrate and phosphate in the adsorption site as reported early by Sharma and Singh (1982) in peach and Kaith et al., (2011) in apple.

Table.1 Effect of heading back and pinching on Nitrogen (\%) content of leaves

\begin{tabular}{|l|l|l|l|l|l|}
\hline \multicolumn{1}{|c|}{ Treatments } & $\mathbf{S}_{\mathbf{1}}$ & $\mathbf{S}_{\mathbf{2}}$ & $\mathbf{S}_{\mathbf{3}}$ & $\mathbf{S}_{\mathbf{4}}$ & Mean \\
\hline M1 & 2.53 & 2.67 & 2.75 & 2.64 & $\mathbf{2 . 6 4}$ \\
\hline M2 & 2.46 & 2.76 & 2.85 & 2.60 & $\mathbf{2 . 6 7}$ \\
\hline M3 & 2.78 & 2.87 & 2.83 & 2.80 & $\mathbf{2 . 8 2}$ \\
\hline MEAN & $\mathbf{2 . 5 9}$ & $\mathbf{2 . 7 7}$ & $\mathbf{2 . 8 1}$ & $\mathbf{2 . 6 8}$ & $\mathbf{2 . 7 1}$ \\
\hline & & & & SE(d) & CD @ 5\% \\
\hline M - Main plot & & & & 0.026 & 0.112 \\
\hline S-Sub plot & & & & 0.027 & 0.060 \\
\hline M @S & & & 0.048 & 0.137 \\
\hline S @ M & & & 0.046 & 0.104 \\
\hline
\end{tabular}

Table.2 Effect of heading back and pinching on Phosphorous (\%) content of leaves

\begin{tabular}{|l|c|c|c|c|c|}
\hline TREATMENTS & $\mathbf{S}_{\mathbf{1}}$ & $\mathbf{S}_{\mathbf{2}}$ & $\mathbf{S}_{\mathbf{3}}$ & $\mathbf{S}_{\mathbf{4}}$ & MEAN \\
\hline M1 & 0.015 & 0.020 & 0.025 & 0.019 & $\mathbf{0 . 0 2 0}$ \\
\hline $\mathbf{M 2}$ & 0.017 & 0.020 & 0.018 & 0.014 & $\mathbf{0 . 0 1 7}$ \\
\hline M3 & 0.015 & 0.026 & 0.017 & 0.021 & $\mathbf{0 . 0 2 0}$ \\
\hline MEAN & $\mathbf{0 . 0 1 6}$ & $\mathbf{0 . 0 2 2}$ & $\mathbf{0 . 0 2 0}$ & $\mathbf{0 . 0 1 8}$ & $\mathbf{0 . 0 1 9}$ \\
\hline & & & & SE(d) & CD @ 5\% \\
\hline M - Main plot & & & & 0.000 & 0.002 \\
\hline S - Sub plot & & & & 0.001 & 0.002 \\
\hline M @S & & & 0.002 & 0.004 \\
\hline S @ M & & & & 0.002 \\
\hline
\end{tabular}

Table.3 Effect of heading back and pinching on Potassium (mg $100 \mathrm{~g}^{-1}$ ) content of leaves

\begin{tabular}{|l|c|c|c|c|c|}
\hline Treatments & $\mathbf{S}_{\mathbf{1}}$ & $\mathbf{S}_{\mathbf{2}}$ & $\mathbf{S}_{\mathbf{3}}$ & $\mathbf{S}_{\mathbf{4}}$ & Mean \\
\hline M1 & 63.30 & 69.14 & 65.68 & 65.96 & $\mathbf{6 6 . 0 2}$ \\
\hline M2 & 59.15 & 70.20 & 67.31 & 70.10 & $\mathbf{6 6 . 6 9}$ \\
\hline M3 & 58.57 & 70.63 & 68.75 & 69.69 & $\mathbf{6 6 . 9 1}$ \\
\hline MEAN & $\mathbf{6 0 . 3 4}$ & $\mathbf{6 9 . 9 9}$ & $\mathbf{6 7 . 2 4}$ & $\mathbf{6 8 . 5 8}$ & $\mathbf{6 6 . 5 4}$ \\
\hline & & & & SE(d) & CD @ 5\% \\
\hline M - Main plot & & & 0.58 & NS \\
\hline S-Sub plot & & & & 0.43 & 0.97 \\
\hline M @ S & & & 0.86 & 2.74 \\
\hline S @ M & & & 0.74 & 1.67 \\
\hline
\end{tabular}


Table.4 Effect of heading back and pinching on Calcium (\%) content of leaves

\begin{tabular}{|l|c|c|c|c|c|}
\hline Treatments & $\mathbf{S}_{\mathbf{1}}$ & $\mathbf{S}_{\mathbf{2}}$ & $\mathbf{S}_{\mathbf{3}}$ & $\mathbf{S}_{\mathbf{4}}$ & Mean \\
\hline M1 & 1.76 & 1.86 & 1.59 & 1.60 & $\mathbf{1 . 7 0}$ \\
\hline $\mathbf{M 2}$ & 1.23 & 1.93 & 2.10 & 2.33 & $\mathbf{1 . 8 9}$ \\
\hline M3 & 2.15 & 1.99 & 2.08 & 2.52 & $\mathbf{2 . 1 8}$ \\
\hline MEAN & $\mathbf{1 . 7 1}$ & $\mathbf{1 . 9 3}$ & $\mathbf{1 . 9 2}$ & $\mathbf{2 . 1 5}$ & $\mathbf{1 . 9 3}$ \\
\hline & & & & $\mathbf{S E}(\mathbf{d})$ & $\mathbf{C D} @ \mathbf{5 \%}$ \\
\hline $\mathbf{M}$ - Main plot & & & 0.019 & 0.084 \\
\hline S-Sub plot & & & 0.037 & 0.084 \\
\hline M @S & & & 0.059 & 0.147 \\
\hline S @ M & & & 0.065 & 0.146 \\
\hline
\end{tabular}

Table.5 Effect of heading back and pinching on Magnesium (\%) content of leaves

\begin{tabular}{|l|c|c|c|c|c|}
\hline Treatments & $\mathbf{S}_{\mathbf{1}}$ & $\mathbf{S}_{\mathbf{2}}$ & $\mathbf{S}_{\mathbf{3}}$ & $\mathbf{S}_{\mathbf{4}}$ & MEAN \\
\hline M1 & 0.63 & 0.87 & 0.72 & 0.92 & $\mathbf{0 . 7 8}$ \\
\hline M2 & 0.83 & 0.63 & 0.74 & 0.51 & $\mathbf{0 . 6 8}$ \\
\hline M3 & 0.68 & 0.89 & 0.81 & 0.92 & $\mathbf{0 . 8 2}$ \\
\hline MEAN & $\mathbf{0 . 7 1}$ & $\mathbf{0 . 8 0}$ & $\mathbf{0 . 7 6}$ & $\mathbf{0 . 7 8}$ & $\mathbf{0 . 7 6}$ \\
\hline & & & & SE(d) & CD @ 5\% \\
\hline M - Main plot & & & & 0.009 & NS \\
\hline S - Sub plot & & & & 0.008 & 0.018 \\
\hline M @S & & & & 0.015 & 0.044 \\
\hline S @ M & & & & 0.013 & 0.031 \\
\hline
\end{tabular}

\section{Potassium content}

Potassium content of moringa leaves were not much affected by heading back treatments (Table 3). Pinching at 60 days after heading back $(69.99 \mathrm{mg} / 100 \mathrm{~g})$ and interactionM $\mathrm{M}_{3} \mathrm{~S}_{2}$ of $70 \mathrm{~cm}$ heading back with pinching at 60 days (70.63 $\mathrm{mg} / 100 \mathrm{~g}$ ) recorded the highest amount of potassium. The interaction of heading back and early pinching increased the $\mathrm{K}$ content due to vigorous growth and less accumulation of dry mater. The results were in accordance with the findings of Jayswal et al., (2017) in guava and Khaosumain et al., (2013) in longan.

\section{Calcium content}

Heading back at $70 \mathrm{~cm} \quad\left(\mathrm{M}_{3}-2.18 \%\right)$, pinching at 100 days $\left(\mathrm{S}_{4}\right)$ after heading back
$(2.15 \%)$ and in the interaction $\mathrm{M}_{3} \mathrm{~S}_{4}$ (heading back at $70 \mathrm{~cm}$ followed by pinching at 100 days) with $2.52 \%$ recorded the highest $\mathrm{Ca}$ content.Ca translocation lag behind the water movement in mass flow (Bangerth, 1979). The immobility of $\mathrm{Ca}$ reduces the deposition in heavily pruned trees than the slight pinched trees at 100 days after heading back. The results confirm the findings of Singh et al., (2010) in mango and Kumar and Thakur (2012) in plum (Table 4).

\section{Magnesium content}

Pinching and the interaction of heading back with pinching treatments induced significant variations in magnesium content of moringa leaves. Pinching at 60 days $\left(\mathrm{S}_{2}\right)$ after heading back $(0.80 \%)$ and interaction $\mathrm{M}_{3} \mathrm{~S}_{4}$ of $70 \mathrm{~cm}$ heading back with pinching at 100 days $(0.92$ 
$\%$ ) recorded the highest amount of magnesium. Magnesium content availability in leaves depends on the severity of pruning. Less intensive heading back and pinching enhanced the amount of $\mathrm{Mg}$ in leaves. The findings were in line up with the results of Rutkowski et al., (2018) in sour cherry (Table 5).

In conclusion the mineral content availability in leaves are related to the intensiveness of pruning and their mobility status. Less intensive heading back combined with intensive pinching promotes the vegetative growth. The vegetative growth ultimately increased the sink availability for the deposition of minerals. Hence, heading back at $70 \mathrm{~cm}$ with pinching at 60 days after heading back can be adopted to increase the leaf mineral content which is essential on the nutritional content of moringa leaves for its various uses.

\section{References}

Bangerth, F. 1979. Calcium -Related Physiological Disorders of Plants. Ann. Rev. Phytopathol. 17:97-122.

Cheng L and R Raba. 2009. Accumulation of macro and micro- nutrients and nitrogen demand supply relationship of Gala/ Malling 26 apple treesgrown in sand culture. Journal of American Society of Horticulture Science 134 (1): 3-13.

Gopalakrishanan L, K Doriya and DS Kumar. 2016. Moringa oleifera: A review on nutritive importance and its medicinal application. Food Science and Human Wellness. 5(2): 49-56.

Jayswal, DS, DP Sharma, TR Sharma, AK Dwivedi, AS Gontia and N Lal. Effect of Pruning intensity and Nutrition on NPK content in Guava leaves cv. Allahabad Safeda. International journal of Chemical Studies.
Kaith NS, Sharma U, Sharma DD, Mehta DK. Effect of different pruning intensities on growth, yield and leaf nutrients status of Starking delicious apple in hilly regionof Himachal Pradesh. Journal of Farm Sciences. 2011; 1(1): $37-42$.

Khaosumain Y, C Sritontip and S Changjeraja. 2013. Effects of Difference Nitrogen Fertilizer Doses Growth, Leaf Nutrient Concentration, Flowering and Fruit Quality in OffSeason Longan. Acta Hort. (ISHS) 984: 271-274

Kumar J and D Thakur. 2012. Effect of different pruning intensities on growth, yield, fruitquality and leaf macronutrient content of plum cv. SANTAROSA. The Asian Journal of Horticulture. 7(2): 484-487.

Panse VG, Sukhatme PV. Statistical methods foragricultural workers. Published by Indian Council ofAgricultural Research, New Delhi. 1967, 166-175.

Rutkowski K, Z Zydlik and AStachowiak. 2018. Effect of tree pruning intensity on the content of mineral components in the sour cherry leaves of 'Łutówka'. Folia Hort. 30(1):47-55.

Sharma MR and R Singh. 1982. Yield and chemical composition of peach leaves as influenced by NPK fertilization. Punjab Horticultural Journal.22: 93- 98.

Singh SK, Singh SK, Sharma RR, Srivastava M, PatelVB. 2010. Influence of pruning intensities on leaf nutrient composition in some mango cultivars planted under highdensity. Indian Journal Horticulture. 67(1):16-20.

Singh SR, Sharma AK and Sharma MK 2009. Influence of NPK combination at different altitude and aspect on fruit yield, quality and leaf nutrient status of apple cvs Red Delicious. Indian Journal of Horticulture Science 66 (2): 175182. 
Thokchom R, DP Sharma and KK Thakur. 2018. Effect of Rejuvenation Pruning and Nitrogen Levels on Leaf Nutrient Status of Old and Senile Apricot
(Prunus armeniacaL.) cv. New Castle Trees. International Journal of Current Microbiology and Applied Sciences. 7(1):2492-2500.

\section{How to cite this article:}

Divyabhrathi, V., V. Swaminathan, P. Paramaguru, K. Venkatesan, T. Anitha and Arumugam, T. 2020. Impact of Heading Back and Pinching on Mineral Status of Moringa Leaves (Moringa oleifera Lam. Cv. PKM-1). Int.J.Curr.Microbiol.App.Sci. 9(11): 3496-3501. doi: https://doi.org/10.20546/ijcmas.2020.911.417 